\title{
Design and Development of WEB-based Remote Network Physical Education Teaching Platform in Colleges and Universities
}

\author{
https://doi.org/10.3991/ijet.v13i04.8478 \\ Ying Zhang \\ Tianjin Sino-German University of Applied Sciences, Tianjin, China \\ suzy78@163.com
}

\begin{abstract}
Web-based remote education mainly depends on computer network and multimedia technology supplemented with geographically dispersed teachers and students, making teachers and students carry out teaching information interaction through the Internet. Compared with other disciplines, remote education is rarely applied in Physical Education (PE) discipline. However, PE discipline is a bilateral teaching activity, featured with strong practicalness and participation. Thus, remote PE teaching can make full use of teaching resources, improve the efficiency of teaching management, and more effectively complete PE teaching activities. This paper first introduces the research background, carries out applied analysis of key technologies, such as WEB technology, streaming media technology and database technology, designs the overall structure model and functional module of the system, and then completes design and development of remote network PE teaching platform in colleges and universities.
\end{abstract}

Keywords-WEB; PE; remote network teaching; database; design and development of platform

\section{$1 \quad$ Introduction}

At present, students in colleges and universities have no longer been satisfied with simple PE activities and courses, which raises higher theoretical needs for scientific PE guidance and more professional hardware requirements for sports equipment, sports venues and other facilities [1]. The traditional PE teaching mode hasn't met the requirements of $\mathrm{PE}$ teaching activities in schools, resulting in development bottlenecks in teaching management, sports facilities and teaching scale.

The rapid development of information network technology brings opportunities for remote education and remote education in all fields. As an organic component of college education, PE teaching also has its inevitable development trend of remote and remote education. PE remote network education in colleges and universities can effectively realize the sharing of sports resources, enrich the information transmission mode of traditional PE teaching, and achieve information transmission of PE activities, including videos, audios, images, texts, and animations through computer tech- 
nology [2]. Besides, PE remote network teaching in colleges and universities can significantly reduce the workload of PE teaching and sports management, achieving networked and informatization management of PE teaching [3].

This paper aims at establishing a WEB-based remote network PE teaching platform so that multi-media and network-based PE teaching resources can be presented to students and teachers without time and geographical limitations when PE teaching management can achieve a high degree of intelligentization, routinization and automation. This paper first summarizes the current situation and development prospect of PE remote education in China [4], and then introduces the related theoretical knowledge of remote education; and studies the key technologies of platform design, such as computer Web server, streaming media technology (windows media format) and SQL database technology. Combined with the development steps of PE remote network education and comprehensive analysis of the overall structure model and functional model of the system, the author finally realizes the design of seven modules of the platform, including user management, public information, courseware management, resource management, and system management, as well as demonstrates relevant interfaces. The establishment of remote network PE teaching platform in colleges and universities has promoted the reform of PE teaching mode and perfected the construction of remote education system in colleges and universities, which is conductive to the popularization of the theoretical knowledge of PE and improving students' physical quality more scientifically and systematically.

\section{Research background and overview of related technologies}

\subsection{Research background}

Development of remote education at home and abroad. By 2015, modern remote education has been conducted in nearly 200 countries around the world represented by the United States where remote education courses are provided by more than $85 \%$ of the universities and the number of students learning through the Internet increases by $130 \%$. Over $95 \%$ of universities and colleges around the world have their own network, among which $40 \%$ of them launch remote education courses. In this background, the remote network teaching model has played a key role in the educational circle [5].

Remote education in China has developed later than that in western countries. At the end of last century, the remote network teaching platform in colleges and universities was piloted in Tsinghua University, Beijing University of Posts and Telecommunications and Hunan University. After more than a decade of development, it has been popularized and developed across the country. In recent years, with the perfection of basic hardware facilities of domestic networks and the popularization of mobile phone network platforms, remote learning has flourished in China [6].

Application prospect of remote education in PE teaching in colleges and universities. The remote education gets a good momentum of development in colleges and universities all over the country. Relying on the characteristics of their campus 
networks, colleges and universities have carried out remote network education for all disciplines. With the development of remote classroom, the application of remote education in college PE teaching is also gradually carried out. PE remote network teaching can make use of diversified means to present PE knowledge from all aspects and perspectives, making PE curriculum closer to the needs of students so that PE teaching management becomes more convenient and efficient [7].

PE teaching is a bilateral teaching activity of teachers and students based on the mode of "action modeling - imitation practice", so PE teaching will have its inevitable development trend of remote and information education because the traditional PE classroom teaching model is difficult to meet students' needs for mastering basic essentials and knowledge of sports due to the limitation of class time and teaching space. As a new type of education that spreads rapidly with low marginal cost and without the limitation of space, remote education can make up for the shortcomings of PE teaching. The remote network PE teaching platform in colleges and universities provides a stage and vast space for teaching activities and sports training with a good application prospect of PE teaching in colleges and universities.

\subsection{Overview of computer technologies}

The computer technical support of remote network PE teaching platform in colleges and universities mainly includes the server, data processing technology and data storage technology. The following is the overview of these three technologies.

Web server. The server forms a corresponding relationship with the client host, providing information exchange to the client through the network. The server can be divided into three levels in terms of computing power, namely working group level, department level, and enterprise level. The server used by the platform is a lightweight WEB application server [8]. The software structure based on Web server is shown in Figure 1.

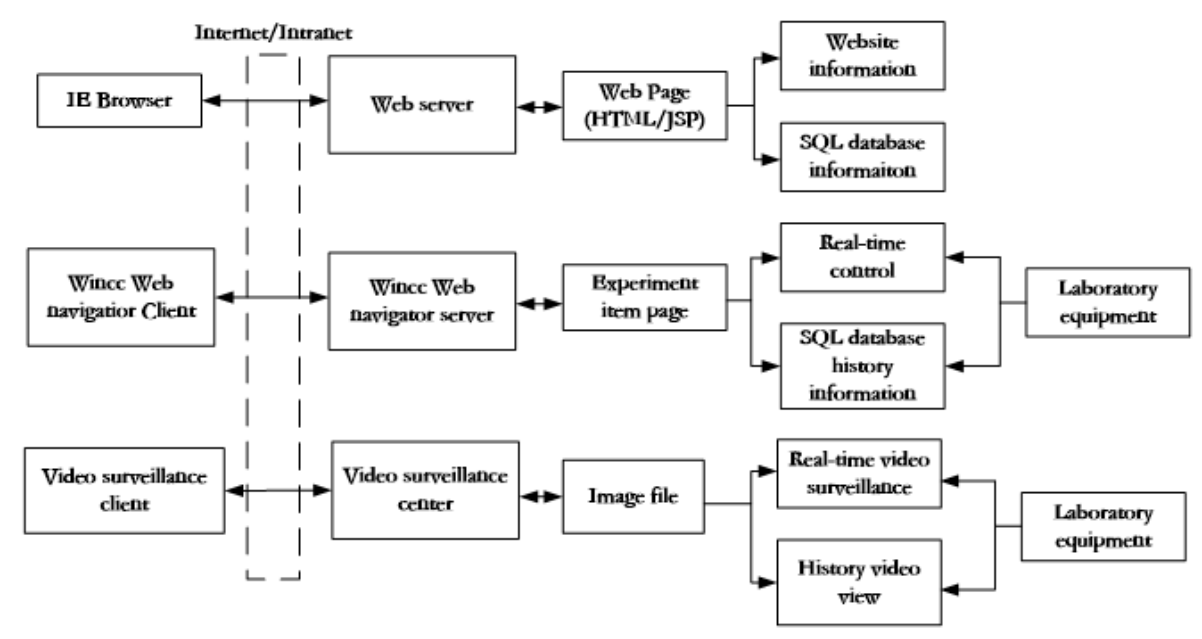

Fig. 1. Software structure of remote network teaching platform based on web server 
From the software structure in the figure, the user can get access to related data or video information in the SQL database through the Internet or Intranet based on the WEB server framework.

Streaming media technology (windows media format). Streaming media system includes encoding and decoding, file storage, streaming media server, streaming media network, user player of source files of audios and videos. Video teaching based on streaming media technology shall achieve several links, namely data collection, data streaming, data transmission and data reading. Windows media is the key to streaming of streaming media data by using ASF-formatted media content [9]. The Windows media format software development kit in the paper supports AFS format files to conduct editing and playing at the same time. System structure of Window media format SDK is shown in Figure 2.

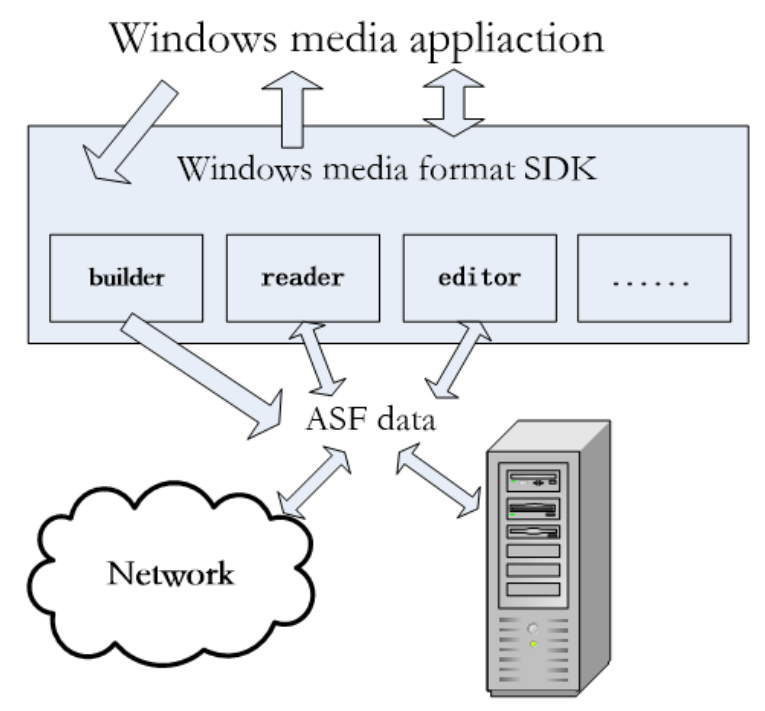

Fig. 2. System structure of window media format SDK

SQL database. The database affecting the scale, the practicality and stability of the system is the key to all information network systems. Microsoft SQL Server 2003 provides a full-featured, technology-mature, secure and stable database platform suitable for remote network PE teaching platforms in colleges and universities [10] with the following adaptability and advantages:

1. SQL database's requirements for equipment, platforms, operation is moderate, in line with hardware and software level of PE remote teaching platform.

2. SQL database is a full-featured and powerful open database management system, belonging to the relational database.

3. SQL database supports the developed engine, standard SQL language, replication, OLAP, analysis of extended features.

4. SQL database is easy to operate with friendly interface that can organically integrate with windows operating system with good compatibility [11]. 


\section{Development steps and overall design of remote network pe teaching platform in colleges and universities}

\subsection{Development steps of remote network PE teaching platform in colleges and universities}

Clearing the development and design steps is the antecedent condition of system design. Development of Web-based PE remote teaching platform is divided into five steps, namely analysis stage, design stage, realization stage, evaluation stage and transmission stage.

1. In the analysis stage, teachers set clear teaching objectives and teaching objects, determine the teaching subject of $\mathrm{PE}$, and analyze the characteristics of the cognition and individuality of teaching objects [12].

2. In the design stage, the development strategies of teaching content of PE remote course is determined. The script of remote courseware, video teaching, action modeling video is completed through writing audio and video scripts. Then PE teaching materials, such as voice, text, video and multimedia courseware are collected and arranged according to the teaching contents. And we make and adjust remote network courses.

3. In the realization stage, teaching contents of PE remote course are developed on the basis of the design stage.

4. In the evaluation stage, the teaching contents, teaching plans and teaching strategies of PE remote courseware are determined during the trial operation of the platform through the comprehensive analysis of mid-term evaluation and summative evaluation [13].

5. In the transmission stage, transmission means the transmission effect and efficiency of remote teaching contents and students' acceptance level of PE remote teaching contents. In this stage, it should ensure that students transit from the traditional playground, training hall to the remote learning environment.

\subsection{Overall design of remote network PE teaching platform in colleges and universities}

Levels of system server . After an overall consideration of the needs of remote network PE teaching platform, the platform server can be divided into five levels. As shown in Figure 3, they are My SQL Database server, WEB server, campus network and Ethernet facilities, Education Platform Management System, Teaching system and Learning system [14].

All levels of the server are connected by hardware and software platform to achieve data information connectivity between the client and server. 


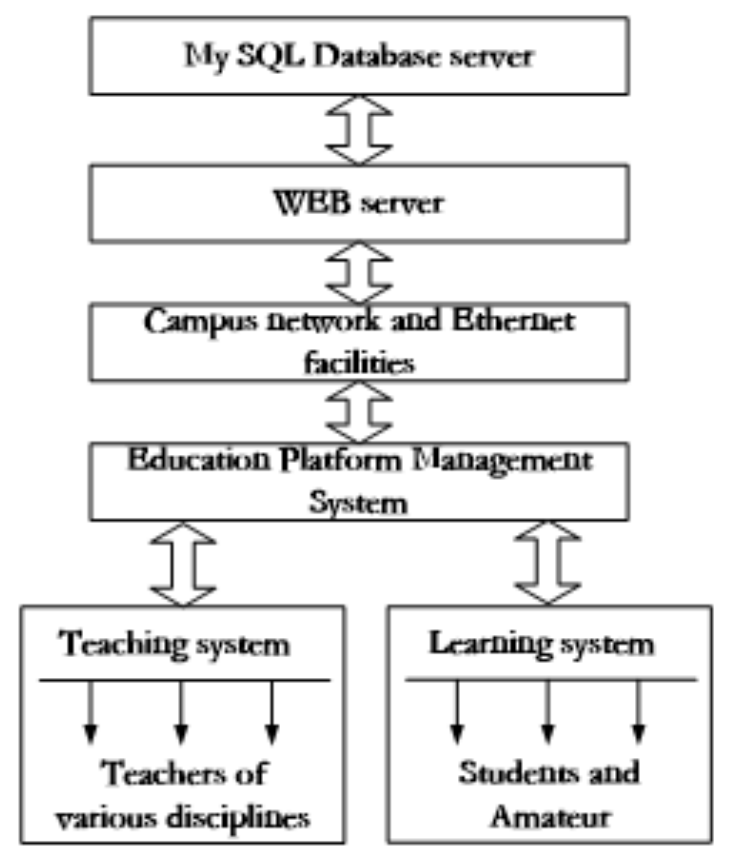

Fig. 3. System server deployment block

Overall logical framework of the platform. According to Chinese E-learning Technology Standardization (CELTS), the remote network teaching platform can be divided into three sub-platforms, namely portal sub-platform, learning sub-platform, and management sub-platform. The logical structure of system is shown in Figure 4.

The portal sub-platform offers student platform and back-stage management and provides services, such as sports news, event information, sports course selection, course inquiry. The main functions of the learning sub-platform include remote courseware learning, remote teaching, remote homework, remote discussion and score inquiry [15]. And the management sub-platform plays a role in teaching management, student management and sports-specific course selection management. The three subplatforms respectively correspond to teachers, students, and administrators. They are independent but have the ability to share data with each other to achieve the teaching objectives of remote network PE teaching platform. 


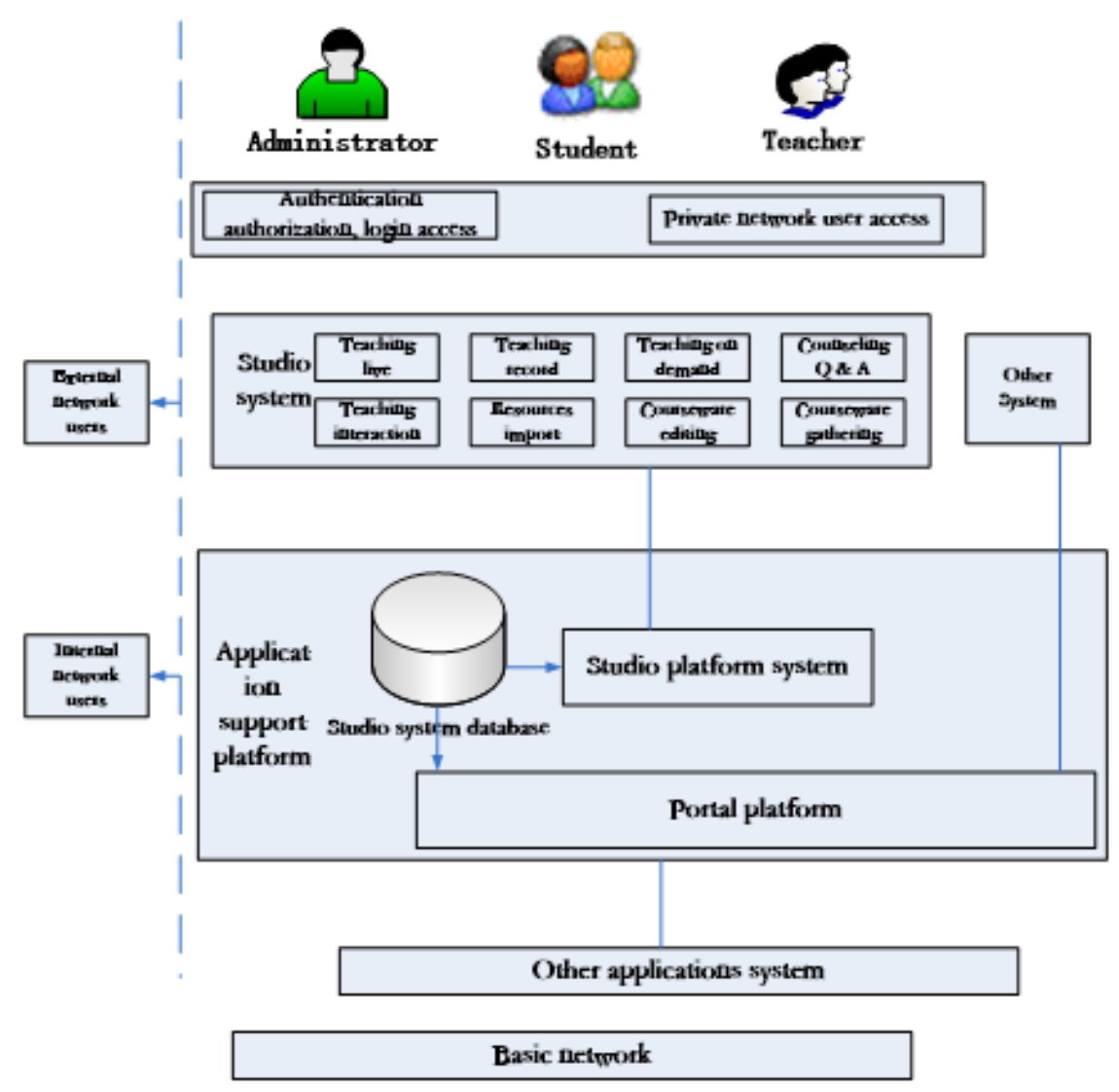

Fig. 4. Logical structure of system

\subsection{Functional module design of remote network PE teaching platform in colleges and universities}

The PE remote teaching platform in colleges and universities has seven functional modules that are both independent and inseparable.

Course content presentation module mainly presents teaching content, teaching program, and teaching instructions. Media resource management module mainly achieves functions of teacher management, student management, traditional teaching materials management and teaching resources management. Teaching management module contains notice, grade book, and class management, achieving functions of training activities management, course registration management, forum management and course management Interactive communication module consists of forums, chat rooms, e-mail, SMS, and remote survey. Learning tools module is composed of bookmarks, search engines, memos, and Q\&A. Learning evaluation module includes practice and tests. System maintenance and management module mainly achieves 
functions of site management, user management, authority management, system initial establishment and sub-site management [16].

\section{$4 \quad$ Realization of remote network pe teaching platform in colleges and universities}

\subsection{Concrete realization of platform design}

Corresponding to functional modules, platform functions include seven parts for the overall design and deployment according to the characteristics of PE teaching: 1. User management-teaching management module; 2. Public information-learning tools module; 3. Courseware management-course content presentation module; 4. Resource management-media resource management module; 5. System management-system maintenance and management module; 6. Counseling Q\&Ainteractive communication module; 7. Live streaming/ request system-learning evaluation module.

1. User management-teaching management module. User management mainly manages user's personal information, as well as provides user registration / login, user's information changes, password recovery, and administrator management.

2. Public information-learning tools module. Public information module provides sports information bulletins (including school sports events and course information, news), data download (including doc, pdf, xlsx format download of PE teaching management application form, schedule, and evaluation form) and help information.

3. Courseware management-course content presentation module. Courseware management includes courseware collection (image data collection and PPT index extraction), and courseware editing (courseware editing and composition).

4. Resource management-media resource management module. The resource inputting mainly converts the format resources unmatched with the standard format of the platform to the standard format of the platform, namely ASF data format in Figure. 2. Resource backup is to manage and backup the released courseware resources.

5. System management—system maintenance and management module. Teaching monitoring management is to make administrative staff supervise sports live streaming content and manage live streaming classroom and video request. In addition, it can manage the latest sports resources, such as modifying, publishing, stopping, deleting and other operations.

6. Counseling Q\&A-interactive communication module. Counseling Q\&A module provides students and teachers with a platform for communication where students can query common problems as well remote consults PE teachers. Besides, it provides asynchronous Q\&A, remote synchronous Q\&A, and Q\&A inquiry.

7. Live streaming / request system-learning evaluation module. 1) Providing live streaming videos and audios, it can ensure security of live broadcast by live 
streaming media server to avoid illegal download and modification. 2) Live streaming courseware and live streaming videos and audios form multimedia teachers so that users can watch the relevant live streaming content through the browser at the client-side. 3) It offers teaching interaction. After teaching end and learning end are connected by Socket, students and teachers can conduct remote communication.

\subsection{Design of platform interface design and analysis of application results}

A Web-based remote network PE teaching platform in colleges and universities is established according to the system functional module design by using the related software and data transmission technologies and adding content to the database. The platform not only accords with the overall design model hierarchy, but meets the design requirements of functional module. In this part, we will show and analyze several key functions of the platform.

1. User management-user registration / login. Users of Web-based remote network PE teaching platform in colleges and universities need to register in the interface shown in Figure 5 before they can $\log$ in to the system to conduct relevant authority operation.

2. System management-teaching monitoring management. In the teaching monitoring and management module, teaching administrator can monitor and master the teaching content and quality of different PE classrooms through video recording information and students can choose their favorite PE courses through remote network without geographical limitations. As shown in Figure 6, teaching courses of basketball, table tennis, tennis and tai chi are conducted in different PE classes. Students can choose their favorite courses according to their needs while switching to other courses.

3. Analysis of application results. The remote network PE teaching platform in colleges and universities better reflects teacher-directed and student-oriented roles, expanding the scope of the classroom and realizing the conservation and efficient use of PE resources. The platform adopts the object-oriented programming technology which takes the objects as the core from the whole to the detailed design with good openness and scalability. In addition, the platform satisfies the general functional requirements of users and provides students, teachers and administrators with more convenient PE learning, teaching, and management, which promotes the development of PE teaching in colleges and universities with a good application effect. 
Paper-Design and Development of WEB-based Remote Network Physical Education Teaching Platfo...

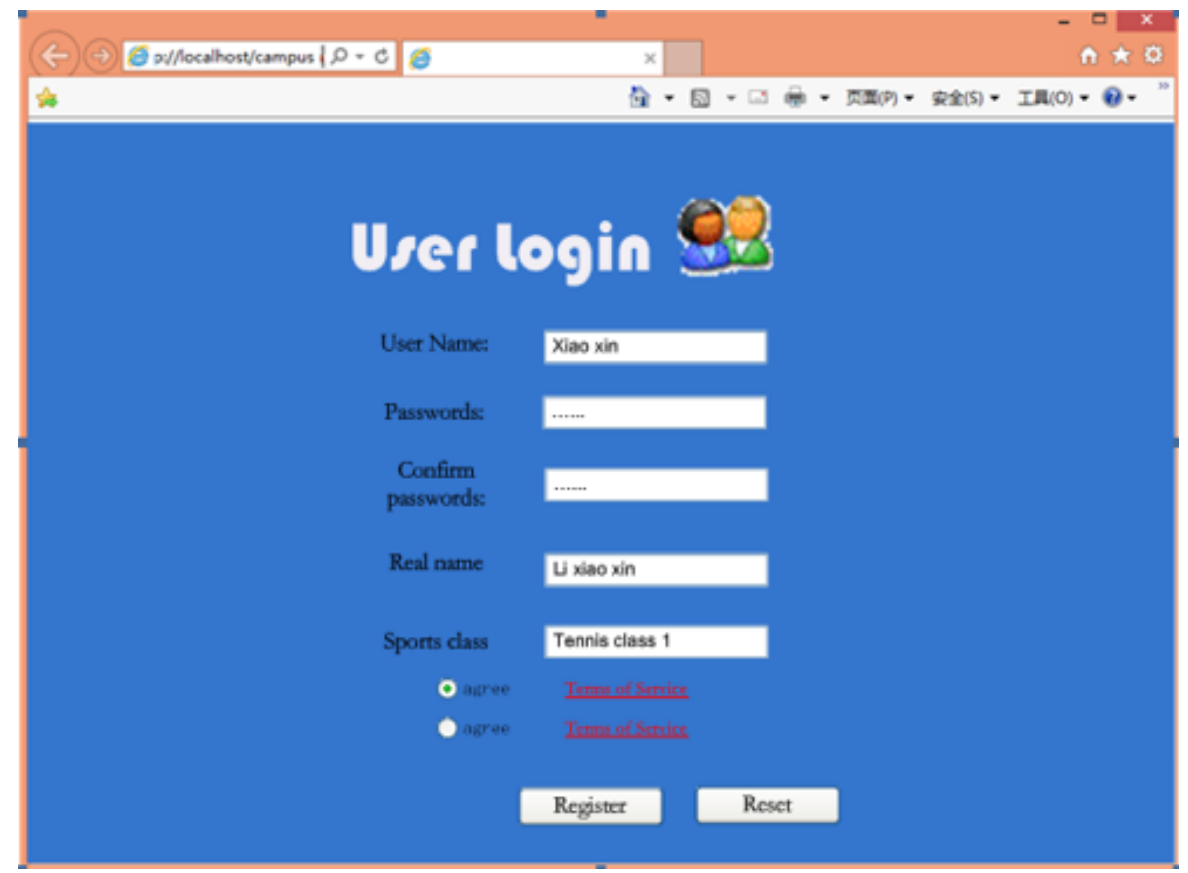

Fig. 5. User register interface

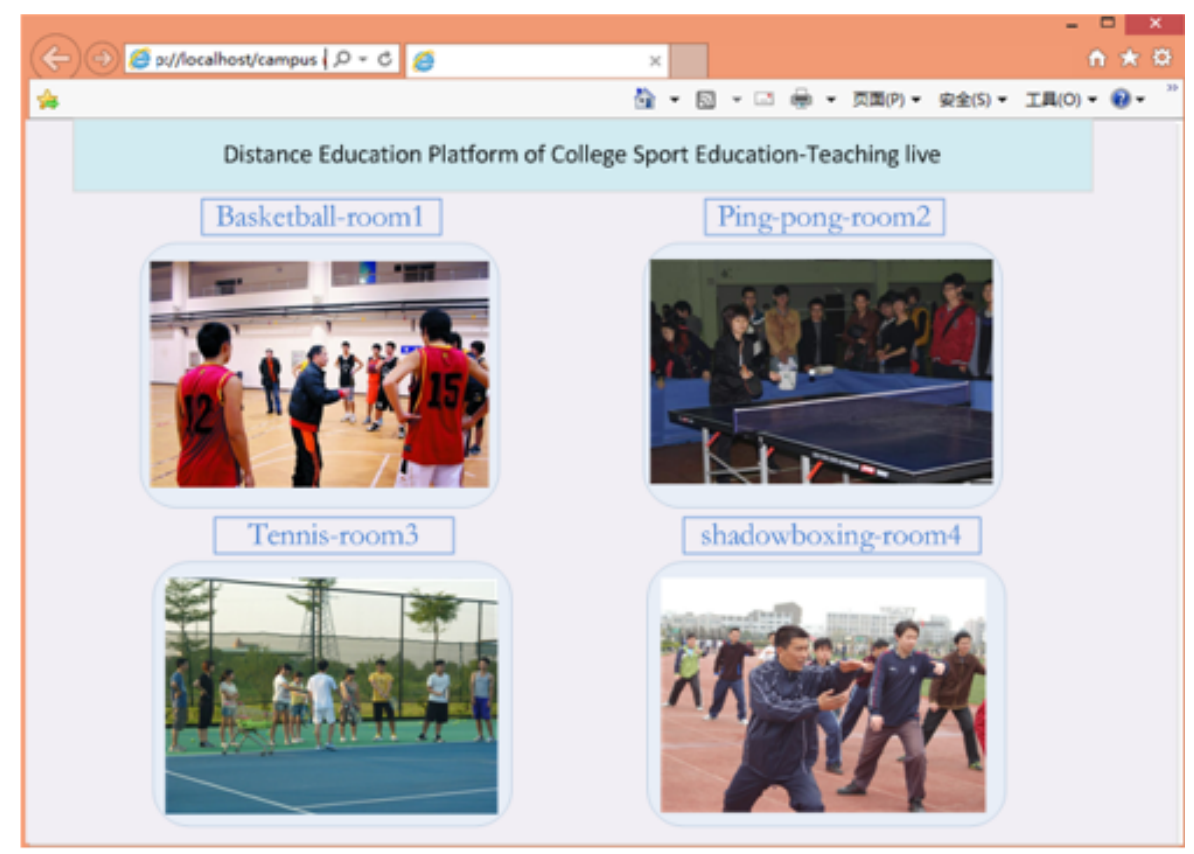

Fig. 6. Teaching monitoring and management interface 


\section{Conclusions}

Based on the Web system framework and combined with the computer streaming media and SQL database technology, a remote network PE teaching platform in colleges and universities is designed. First of all, the paper introduces the application prospect of PE remote teaching in colleges and universities and explains the necessity of designing and developing a remote network PE teaching platform. And then it elaborates the related computer technologies and completes design and development of the platform after fully analyzing the overall framework and functional modules. This paper has the following conclusions and research significance:

1. The development and design of the platform enriches the application cases of remote education in PE teaching in colleges and universities, as well as promotes the development of PE teaching in colleges and universities.

2. The openness, sharing and security of computer technologies are adopted to guarantee the sharing convenience and security of texts, audios and videos in PE teaching.

3. The development of the platform has broken through the limitations of time and space of the traditional PE teaching mode so that it is an effective way to reform the PE teaching mode.

\section{$6 \quad$ References}

[1] Chen, A., Liu, X. (2008). Expectancy beliefs and perceived values of Chinese college students in physical education and physical activity. Journal of Physical Activity \& Health, 5(2), 262. https://doi.org/10.1123/jpah.5.2.262

[2] Zhou, D.Q. (2015). Investigation on sport injuries in physical education department students of normal colleges. Annals of Surgery, 13(5), 356-61.

[3] Ried, L.D., Mckenzie, M. (2004). A preliminary report on the academic performance of pharmacy students in a distance education program. American Journal of Pharmaceutical Education, 68(3), 65. https://doi.org/10.5688/aj680365

[4] Learn, C.D. (2009). Distance learning: issues and applications for nontraditional programs. American Journal of Pharmaceutical Education, 58(4), 406-410.

[5] Shinchi, T., Kondo, K., Iwakiri, J. (2006). Prospects of distance learning through communications satellite in school education based on the international exchanges carried out at elementary school. Australian Veterinary Journal, 84(5), N4-N4.

[6] Tang, Y.E. (2005). A comparison between the development of distance education at home and abroad, Research on Education Tsinghua University.

[7] Nji, A. (2007). Prospects of distance education for agricultural training, education and agri-business in Cameroon. Inflammatory Bowel Diseases, 1(1), 43-53.

[8] Cardellini, V., Casalicchio, E., Colajanni, M., Yu, P.S. (2002). The state of the art in locally distributed web-server systems. Acm Computing Surveys, 34(2), 263-311. https://doi.org/10.1145/508352.508355

[9] Aeluri, P.K., Bojan, V., Richie, S., Weeks, A. (2004). Objective quality analysis of mpeg1, mpeg-2 \& windows media video. IEEE, 224-225. https://doi.org/10.1109/IAI.2004.1 $\underline{300978}$ 
Paper-Design and Development of WEB-based Remote Network Physical Education Teaching Platfo...

[10] Stonebraker, M. (2010). Sql databases v. nosql databases. Communications of the Acm, 53(4), 10-11. https://doi.org/10.1145/1721654.1721659

[11] Ernst, J. (2010). Sql databases v. nosql databases comment. Communications of the Acm, 53(4), 11-11.

[12] Sakalauskas, L., Preidys, S. (2009). The analysis of distance education users' needs, Information Sciences, (50), 7.

[13] Khan, A.W. (1987). Training needs for the application of communication technology in distance education in india. Veterinary Journal, 176(2), 216-220.

[14] Taylor, J.R., Scolaro, K.L., Williams, J.S. (2006). Development of a teaching certificate program utilizing distance education. Annals of Pharmacotherapy, 40(6), 1215-1215. https://doi.org/10.1345/aph.1H033

[15] Jugdev, K. (2010). A case study of faculty development needs in distance education; presented at the international council for open and distance education, santo domingo, do, Pharmacogenomics, 11(10), 1359-65.

[16] Mufer, W.H. (2013). Professional development of teachers through open and distance learning: the case of the University of Buea distance education (ded) programme. Journal of Molecular Structure, 14(3), 465-467.

\section{$7 \quad$ Author}

Ying Zhang Female, Graduated from Tianjin University of Sports, Starting to work in 2001, Tianjin Sino-German University of Applied Sciences, associate profesor of sports teachers. The research direction is sports education. Member of Tianjin aerobics Association Cheerleading Association. (suzy78@163.com)

Article submitted 20 February 2018. Final acceptance 26 March 2018. Final version published as submitted by the author. 